\title{
Ten-year stability and variability, drinking patterns, and impairment in community youth with diagnostic orphan status of alcohol dependence
}

Maike Grabitz ${ }^{\text {a,e }}$, Silke Behrendt ${ }^{\text {a, }}$, Jens Klotsche ${ }^{\text {a }}$, Gerhard Buehringer ${ }^{\text {a,b }}$, Roselind Lieb

${ }^{\mathrm{c}, \mathrm{d}}$, Hans-Ulrich Wittchen ${ }^{\mathrm{a}, \mathrm{d}}$

a Institute of Clinical Psychology and Psychotherapy, Technische Universitaet Dresden, Chemnitzer Str. 46, D-01187 Dresden, Germany

b IFT, Institut fuer Therapieforschung, Parzivalstraße 25, D-80804 Munich, Germany

c University of Basel, Department of Psychology, Division of Clinical Psychology and Epidemiology, Basel Switzerland

d Max Planck Institute of Psychiatry, Kraepelinstr. 2-10, D-80804 Munich, Germany

e Department of Psychiatry and Psychotherapy, University Hospital Carl Gustav Carus, Technische

Universitaet Dresden, Fetscherstrasse 74, D-01307 Dresden, Germany

\begin{abstract}
Objective: Some adolescents and young adults who do not fulfill criteria for DSM-IV alcohol abuse (AA) report symptoms of DSM-IV alcohol dependence (AD) below the diagnostic threshold (diagnostic orphans, DOs; 1 or 2 symptoms). Contemporarily, little is known on the long-term stability, risk of progression to $\mathrm{AD}$, impairment, and drinking patterns possibly associated with this status in the first decades of life. Aim: (1) To identify prevalence rates of the DO status from adolescence to early adulthood. To investigate (2) stability and variability of the DO status over time and (3) associations between DO status, drinking patterns and impairment in comparison to subjects with $\mathrm{AA}$, with $\mathrm{AD}$, or without any symptoms. Method: $\mathrm{N}=2039$ community subjects (aged 14-24 years at baseline) were assessed at baseline and at about four and ten years after baseline. DSM-IV AUD diagnoses were obtained with the DIAX/M-CIDI. Results: About 11-12\% of the sample was classified as DOs at all waves. Over a period of ten years, $18 \%$ of DOs were stable in their diagnosis and additional $10 \%$ progressed to AD. DOs were comparable to subjects with AA in drinking patterns, impairment and stability of diagnostic status. DOs progressed to AD significantly more often than AA. AD was associated with highest levels in all outcomes of interest. Conclusions: The DO status in adolescence and early adulthood is associated with considerable stability, risk of progression and problematic alcohol intake. In consequence, it can be meaningful for the timely identification of early stages of clinically relevant alcohol problems. For subjectswith DO status early specific interventions are required.
\end{abstract}

Keywords: Alcohol dependence, Adolescents, Diagnostic orphans, Drinking, Diagnostic categories 


\section{Introduction}

This article investigates the prevalence rates, stability and risk of progression to DSM-IV alcohol dependence (AD), drinking patterns and impairment associated with a diagnostic orphan (DO) status of AD among adolescents and young adults in a prospective-longitudinal community study.

Alcohol use is associated with several acute and long-term risks, e.g. early death (Rehm, Taylor, \& Patra, 2006), non fatal accidents and injuries (Rehm et al., 2006), critical medical emergencies due to overdose and binge drinking (Okoro et al., 2004), alcoholic cirrhosis (Mathurin \& Deltenre, 2009), and the development of alcohol use disorders (AUDs; Nelson \& Wittchen, 1998). Moreover, a specific effect of adolescent and young adult alcohol use may be an impaired social development (Crews, He, \& Hodge, 2007; Moss, 2008).

Lifetime population prevalence rates among adolescents and young adults range between 10 and 18\% for alcohol abuse (AA) and between 5 and 7\% for AD (Bonomo, Bowes, Coffey, Carlin, \& Patton, 2004; Holly \& Wittchen, 1998; Young et al., 2002). For young adults aged 18 to 29 years lifetime population prevalence rates for AD are found at $18 \%$ for men and at $8 \%$ for women (Hasin \& Grant, 2004). In addition to those developing AUDs, some adolescents and young adults report symptoms of AD but miss the currently defined thresholds for full dependence diagnosis and do also not receive an AAdiagnosis (so called "diagnostic orphans", DOs; a term used since the 1990s (e.g. Kaczynski Pollock \& Martin, 1999)). The DO status is quite prevalent among adolescents and young adults, with 12-month prevalence rates ranging from 8 to $18 \%$ among 12 - to 29 -year-olds in the general population (Harford, Grant, Yi, \& Chen, 2005). In a clinical study $31 \%$ of adolescent regular alcohol users were identified as DOs (Kaczynski Pollock \& Martin, 1999).

Studies investigating adolescent and young adult DO status suggest that this statusmay be an important prodromeof AD or an expression of an AUD (Harford, Yi, \& Grant, 2010). This assumption is supported by the observation that DOs differed from subjects without symptoms by having more intense drinking patterns, a higher risk of developing new AUD symptoms, a greater risk of family history of alcoholism as well as of using multiple psychotropic substances (Bailey, Martin, Lynch, \& Pollock, 2000; Kaczynski Pollock \& Martin, 1999). Epidemiological studies have shown a greater risk of transition to AUDs for adolescents and young adults with first or single AD-symptoms (Behrendt et al., 2008; Hasin \& Paykin, 1999).

There are to date few prospective-longitudinal studies on the DO status in adolescence and young adulthood. This leads to a lack of information on the stability and risk of progression associated with this status over time. In consequence, the need of timely intervention to prevent progression is unclear (Kaczynski Pollock \& Martin, 1999; McBride \& Adamson, 2010; Schuckit et al., 2008). Investigating the impairment of DOs in adolescent and young adult samples over time is necessary to gain firmer information on the clinical and public health significance of the DO status. So far, such evidence is only available from studies in adult DOs (McBride, Adamson, Bunting, \& McCann, 2009a). Also, to evaluate the significance of the DO status in adolescents and young adults, information on drinking patterns in this group is needed (Caetano \& Babor, 2006), as well as information on impairment as one cardinal diagnosis criterion (McBride, Adamson, Bunting, \& McCann, 2009b). 
Against this background, we aim to investigate in a community sample of adolescents and young adults (i) long-term implications of DO status regarding stability and progression to $\mathrm{AD}$ (ii) characteristics of $\mathrm{DO}$ status in terms of drinking patterns and impairment in comparison to subjects with $\mathrm{AA}, \mathrm{AD}$, and without AUD-symptoms.

\section{Materials and methods}

\subsection{Study design and sample}

We used data from the prospective-longitudinal Early Developmental Stages of Psychopathology (EDSP) study. The EDSP project and its family genetic supplement have been approved by the Ethics Committee of the Medical Faculty of the Technische Universitaet Dresden (no: EK-13811). All participants provided informed consent.

In short, the EDSP study examines prevalence, course, risk factors and vulnerabilities of mental disorders including substance use disorders. The representative community sample from the Greater Munich area in Germany included N=3021 subjects aged 14-24 at baseline (T0). To emphasize early stages of psychopathology, subjects aged 14-15 were sampled at twice the probability of subjects aged 16-21. Subjects aged 22-24 were sampled at half the probability of subjects aged 16-21. The study design includes up to three waves of follow-up investigations (T1, T2, T3). At T1, only the younger cohort aged 14-17 at T0 was assessed. Measurement waves were conducted in 1995 (T0), 1996/97 (T1), 1998/99 (T2), and 20032005 (T3). At T3 subjects were 21-34 years old. For the analyses presented here, we use data from $\mathrm{N}=2039$ subjects who participated at waves $\mathrm{T} 0, \mathrm{~T} 2$ and $\mathrm{T} 3$. Response rates were $71 \%$ at T0, 84\% at T2 (based on the T0 sample) and $73 \%$ at T3 (based on the T0 sample). Detailed descriptions of EDSP have been provided elsewhere (Lieb et al., 2000; Wittchen, Perkonigg, Lachner, \& Nelson, 1998).

\subsection{Diagnostic assessment}

Information was obtained with the computer-assisted lifetime and follow-up version of the Munich-Composite International Diagnostic Interview (DIA-X/M-CIDI) (Wittchen \& Pfister, 1997). The DIA-X/MCIDI is a fully standardized diagnostic interview designed to assess mental disorders and their symptoms according to DSM-IV as well as ICD-10 criteria. 12months and lifetime prevalence rates were assessed at T0; 12-month and follow-up prevalence rates were assessed at subsequent waves. Validity and reliability of substance use disorders diagnosed with the DIA-X/M-CIDI have been established; Retest reliability for AUDs was .78 after 39 days (N=60) (Lachner et al., 1998; Wittchen, Lachner, Wunderlich and Pfister, 1998). For alcohol consumption and AUD symptoms, syndromal clustering, drinking quantity and frequency as well as onset and recency of alcohol use and AUDs were assessed. Average drinking quantity per drinking daywas assessedwith the help of a booklet that depicts glasses and bottles of different types of alcoholic beverages. The amount of alcohol was transformed into standard drinks (one drink refers to $9 \mathrm{~g}$ of ethanol).

\subsection{Variables used in the analysis}

The independent variable in all analyses is diagnostic status (NS, DO; AA, AD). ${ }^{1,2}$ According to DSM-IV (APA, 2000), subjects with a lifetime diagnosis of AD who currently report only

\footnotetext{
${ }^{1} \mathrm{NS}=$ no AUD-symptoms; $\mathrm{DO}=1$ or 2 symptoms of AD but no AA or AD diagnosis; AA = DSM-IV alcohol abuse; $\mathrm{AD}=\mathrm{DSM}-\mathrm{IV}$ alcohol dependence. These abbreviations will be used to refer to the respective diagnostic status as well as to the subjects falling into the category
} 
one or two $\mathrm{AD}$ symptoms receive the diagnosis $\mathrm{AD}$ in partial remission. Therefore, here, subjects with a former diagnosis of $\mathrm{AD}$ who report only 1-2 AD-symptoms at a subsequent wave are not classified as DO but as AD at the subsequent wave. Dependent variables are diagnostic status at $\mathrm{T} 2$ and $\mathrm{T} 3$, and drinking frequency and quantity, as well as impairment at $\mathrm{T} 0, \mathrm{~T} 2$ and $\mathrm{T} 3$.

At all waves current and peak alcohol consumption were calculated according to CIDI conventions for lifetime, the past 12 months and other peak episodes in the respective reference period. Drinking quantity and frequency refer to the period in which the participant reported maximum alcohol intake. Drinking frequency is scaled four times ("less than four times a month"; "one to two times a week"; "three to four times a week"; "almost daily"). Average drinking quantity per day is reported in gram of pure ethanol. Rates for diagnostic status, drinking quantity and frequency are lifetime prevalence rates (at T0) and follow-up prevalence rates $(\mathrm{T} 0-\mathrm{T} 2$ and $\mathrm{T} 2-\mathrm{T} 3)$.

Impairment was assessed at each wave and refers to number of days with impairment in the last four weeks. Four different kinds of impairment were assessed: 1) partial impairment of normal daily activities due to alcohol or drugs 2) partial impairment of normal daily activities due to mental problems 3 ) complete impairment of normal daily activities due to mental problems; 4) complete impairment of normal daily activities due to physical problems. Note that impairment was not necessarily reported as a consequence of alcohol use. ${ }^{3}$

\subsection{Statistical analysis}

Statistical analyses were conducted with the software package Stata 10 (StataCorp, 2007). Data were weighted to account for oversampling of young adolescents and response rates at T0 varying over age, gender and geographic region. 982 subjects who did not participate at T2 and or T3 were excluded from analysis, resulting in $\mathrm{N}=2039$ subjects. Excluded subjects did not statistically differ in baseline regular alcohol use (Behrendt et al., 2008). All associations between DO Status und drop out were non significant, as were the associations for all other groups $(\mathrm{F}(5,3016)=0.73, \mathrm{p}=.599)$. All analyses were adjusted for age at particular measurement and gender.

Associations between diagnostic status and outcome variables were estimated by regression analyses. Multinomial logistic regression models were applied for the categorical outcome variables such as diagnostic status and drinking frequency. Here, relative risk ratios (rrr) and 95\% confidence limits were calculated (Höfler, 2004). Standardized beta-coefficients were calculated to estimate the mean difference between diagnostic groups for the dimensional outcome variables such as drinking quantity and number of impairment days. The standardized beta-coefficient quantifies the mean difference in standard deviations between groups (Höfler, 2004). Multiple comparisons between groups for outcome variables were

\footnotetext{
${ }^{2}$ Following McBride and Adamson (2010), we independently investigated DOs with one symptom and DOs with two symptoms. Both groups were in all variables different from NS and were accordingly treated as one single group. Multiple comparisons revealed that DOs with two symptoms drank more at each time point and had a higher risk to progress to $\mathrm{AD}$ at $\mathrm{T} 3$ (results available upon request).

${ }^{3}$ Respective questions were: 1) During the last four weeks, how many days have you been at least partially impaired in your normal daily activities (school, work, housekeeping, studies) due to the consumption of alcohol or drugs? 2) During the last four weeks, how many days have you been at least partially impaired in your normal daily activities (school, work, housekeeping, studies) due to mental problems? 3) During the last four weeks, how many days have you been completely impaired in your normal daily activities (school, work, housekeeping, studies) due to mental problems? 4) During the last four weeks, how many days have you been completely impaired in your normal daily activities (school, work, housekeeping, studies) due to physical problems?
} 
performed by F-tests after fitting the regression model (results of all multiple comparisons are available upon request). The model fit of the regression models were assessed by the Link test of Pregibon (Pregibon, 1980). It could be interpreted as a test for the hypothesis if a set of predictor variables is correctly specified. A graphical test of model fit was also applied for multinomial regression analysis by using the predicted probabilities. Standard errors and confidence intervals were estimated robust by a sandwich estimator (Royall, 1986) to account for the weighting scheme and sampling design.

\section{Results}

\subsection{Lifetime and follow-up prevalence rates}

At all waves, the DO status was quite prevalent (10.8-11.9\%). At waves T0 and T3, DO was the most common status apart from no diagnosis; at T2, DO was slightly less prevalent than AA (11.4 vs. $13.3 \%)$. AD was less frequent than DO at all waves. Interestingly, rates for DO remained fairly unchanged at each wave, while AA-rates decreased between T2 and T3 and AD-rates increased from $\mathrm{T} 0$ to $\mathrm{T} 3$. At $\mathrm{T} 0$, subjects aged 18-24 years at $\mathrm{T} 0$ were more likely to have a DO or AUD-status than the younger cohort. At T2 and T3, the younger cohort (baseline age 14-17 years) caught up on the older cohort (all percentages weighted) (Table 1).

\subsection{Stability of the DO status and the risk of progression to $A D$}

Stability of baseline DO status over time was considerable $(21.8 \%$ at $\mathrm{T} 2,18.4 \%$ at $\mathrm{T} 3)$. In addition, a considerable proportion of baseline DOs progressed to AD at T2 $(8.1 \%)$ and T3 (10.2\%). Among DOs at T2, 25.2\% were still DOs at T3. 5.1\% progressed to AD at T3 (see Table 2). In regressions between baseline and T2; baseline and T3; T2 and T3 DOs had a risk for staying stably in the DO status of $\mathrm{rrr}=4.0$; $\mathrm{rrr}=2.4$; $\mathrm{rrr}=3.7$ respectively; for progression to $\mathrm{AD}$ of $\mathrm{rrr}=6.4 ; \mathrm{rrr}=4.7 ; \mathrm{rrr}=2.4$ respectively (Table 2). Multiple comparisons showed that DO status was all over less stable than $\mathrm{AD}$ and comparable to AA; Risks for progression to $\mathrm{AD}$ were higher in DOs than in AA.

Moreover, DOs rarely progress to AA over time in the long run (in $0.23 \% \mathrm{w}$ of cases over 10 years), while AA progress far more often to the DO status (16.82\%w over 10 years). Detailed results on the stability of the DO status and the risk of progression to AD in different age groups are available upon request.

\subsection{Drinking frequency}

At T0, $18.5 \%$ of DOs drank "less than four times a month", $43.1 \%$ reported drinking "one to two times a week", $25.3 \%$ reported to drink "three to four times a week", and $13.1 \%$ reported "almost daily" drinking (Table 3). DOs were more likely than NS to endorse all elevated drinking frequencies in comparison to drinking less than four times a month $(\mathrm{F}(15$, 1105) $=15.29$, pb.001) (Table 3). Multiple comparisons showed that DOs were similar to AA while $\mathrm{AD}$ had significantly higher percentages in higher drinking frequencies.

At T2 $(\mathrm{F}(15,1681)=13.59, \mathrm{pb} .001)$ and $\mathrm{T} 3(\mathrm{~F}(15,1803)=16.10, \mathrm{pb} .001)$, results of regressions (Table 4) and multiple comparisons were in accordance with results at T0 with DOs drinking more frequently than NS, relatively comparable to AA (only at T2, DOs drank significantly more often 1-2 and 3-4 times a week; at T3 subjects with AA drank significantly more often 1-2 times a week and DOs drank significantly more often almost daily) and less than AD. 
Up to T3, prevalence rates for more frequent (3-4 times a week or almost daily) drinking of DOs increased (Table 2).

\subsection{Drinking quantity}

At T0, DOs drank on average $20.6 \mathrm{~g}$ pure ethanol per day, thereby being comparable to AA (Table 3$)$. Drinking quantity was significantly associated with diagnostic status $(\mathrm{F}(5$, $1113)=39.50, \mathrm{pb} .001)$. Multiple linear regressions showed that DOs drank significantly more than NS (Table 5). Multiple comparisons showed that DOs drank similar quantities compared to AA and less than AD.

At T2, DOs drank on average $18.9 \mathrm{~g}$ pure ethanol per drinking day (Table 3). Results of regression $(\mathrm{F}(5,1689)=43.12$, pb.001) (Table 5) and multiple comparisons accorded with results at T0. At T3, DOs drank on average $33.8 \mathrm{~g}$ pure ethanol per regular drinking day (Table 3). Results of regression $(\mathrm{F}(5,1809)=42.28, \mathrm{pb} .001)$ (Table 5) and multiple comparisons accorded with results at T0; While the average intake of $43.16 \mathrm{~g}$ pure ethanol of subjects with AA seems to be higher than that of DOs at T3, multiple comparisons did not show a significant difference due to small sample numbers of AA subjects at T3.

Over waves, average quantity of drinking per day of DOs increased to a considerable $33.8 \mathrm{~g}$ (Table 3).

\subsection{Impairment in the last four weeks}

Partial impairment of normal daily activities due to alcohol or drugs: at T0, the mean number of days with impairment was 1.3 for AD andb1.0 for all other groups. At T2, AD reported 1.6 days with impairment, AA 1.1 and DOs and NS less than one day. At T3, AD reported 1.2 days with impairment, all other groups below one day. Although regressions at $\mathrm{T} 0(\mathrm{~F}(5$, $2033)=6.42, \mathrm{pb} .001)$ and at $\mathrm{T} 3(\mathrm{~F}(5,2031)=10.70, \mathrm{pb} .001)$ showed significant differences between DOs and NS, the mean number of days with impairment in DOs at T0 (0.19) and T3 (0.6 days) respectively may not be clinically relevant.

Since baseline, impairment due to alcohol or drugs of DOs increased. With regard to the other forms of impairment (partial impairment of normal daily activities due to mental problems; complete impairment of normal daily activities due to mental problems; complete impairment of normal daily activities due to physical problems) comparisons between DOs and NS were not significant at $\mathrm{p} \geq 0.05$ at all waves. Detailed results on all analyses on impairment days are available upon request.

\section{Discussion}

We investigated the stability and risk of progression to alcohol dependence (AD), drinking patterns (frequency and quantity), and impairment associated with the diagnostic orphan status of AD (DO; subjects without alcohol abuse or AD but with 1-2 AD symptoms) in a community sample of adolescents and young adults. In summary, the main findings are: (1) Stability of the DO status over a ten-year period was considerable (18.4\%); in addition, subjects with a DO status were at elevated risk of progression to AD. (2) DOs drank more frequently and had higher consumption rates per day than subjects without symptoms; DOs were comparable to subjects with AA in this regard. (3) In spite of the elevated drinking patterns of DOs, they reported only minimal impairment during adolescence and young adulthood. 
For nearly every fifth subject, the DO status was stable over a 10 year follow-up period. Taking into account the elevated drinking patterns associated with this status, the stability of the DO status may have negative outcomes as mental discomforts (Crews et al., 2007; McBride \& Adamson, 2010) and medical conditions (McBride et al., 2009a, 2009b) in the long run. Besides this stability, our results indicate that for a considerable proportion of DOs, the DO status leads to further progression to AD. The elevated risk for DOs to develop AD has been found repeatedly (Bailey et al., 2000; Behrendt et al., 2008; Harford, Yi et al., 2010; Kaczynski Pollock \& Martin, 1999; McBride \& Adamson, 2010). In our study, meeting the DO status leads to a risk for developing AD about five times higher than subjects without symptoms. However, the group of DOs progressing to AD is rather small. This may raise the question of false positive diagnosis and call into question the importance of the DO status as an early indicator of AD risk. Still, the results underline that Dos are expressing severe drinking and AD symptoms. Moreover, those measures in DOs are at least as severe as in subjects with AA, which is a serious disease. These findings indicate that at least for some subjects the DO status is not merely a harmless and transient developmental phenomenon. Moreover notable from our results, DOs rarely progress to AA over time in the long run, while AA progress far more often to the DO status, which underlines the importance of capturing subjects with DO in the DSM-V classification of alcohol use disorders. In conclusion, the DO status should be considered as a clinically relevant phenomenon in adolescence and early adulthood: It can be a pre-stage for full-blown AD and it can be a subclinical yet stable status that is associated with heavy alcohol use and its well-documented sequelae (2006; Lewinsohn et al., 1996, Rehm et al., 2003). Hence, besides the overall prevention efforts targeting problematic drinking in adolescents, we recommend a supplemental prevention strategy for this group at special risk as for example providing information about the risk associated with certain first symptoms (Behrendt et al., 2008).

\subsection{Drinking patterns}

In comparison to subjects without symptoms, DOs had elevated drinking frequencies and quantities. As drinking frequency and quantity both have a strong association with diseases (Alcohol \& Public Policy Group, 2003; Rehm et al., 2003, 2006; WHO, 2008) and development auf AUDs (Dawson et al., 1995; Holly et al., 1997; Lewinsohn et al., 1996), DOs may be at risk for negative consequences of alcohol use. Thus drinking frequency and quantity may provide external validation for symptom report in DOs. This is in line with the finding that DOs were more prevalent in groups of current and heavier drinkers (Harford et al., 2005).

\subsection{Impairment}

In spite of elevated drinking patterns of DOs, the impairment reported by DOs was minimal. Interestingly, impairment was minimal in general, with even AD showing only an impairment of about one day per month. One possible explanation for the lack of reports of impairment may be that the questions used in the assessment of impairment were not specifically designed for adolescents and young adults. Therefore, when assessing impairment due to alcohol use, adolescents and young adults may need different questions, referring for instance to impairment in concentration, school performance or social interaction. The questions should also ask directly for impairment or suffering that has been caused by alcohol consumption. 
Still, even without indication of elevated impairment rates in our relatively young sample, the increased drinking patterns observed in DOs at all assessment waves may lead to greater impairment in DOs in the future. This assumption accords to the finding of more salient impairment in adult DOs (McBride et al., 2009a, 2009b), where physical impairment was also much more prevalent. This may point to detrimental long-term effects of untreated, subthreshold AD diagnoses.

\subsection{Implications for alcohol use disorder diagnosis in adolescence and young adulthood}

Clearly, subjects with the DO status differ from subjects without symptoms. Also, subjects with AD strongly differed from all other categories investigated here, while DO and AA were comparable overall. This finding might point to the dimensional gradient of AUD (Kessler et al., 2003; Maser et al., 2009; Saunders, 2006). As the supposedly cost-effective incorporation of mild disorders into the classification systems (Kessler et al., 2003; Saunders, 2006), and the incorporation of alcohol consumption into classifications (Li et al., 2007; Saha et al., 2007) have recently been intensively discussed, the DO status could serve to provide important diagnostic information in the context of information on drinking behavior and dimensional diagnostics on the severity of alcohol use disorders.

As other studies (Bailey et al., 2000; Gelhorn et al., 2008; Kessler et al., 2003; Maser et al., 2009; Schuckit et al., 2008) these findings suggest a reorientation in diagnosis of AUDs. Results like ours and others (Chung \& Martin, 2001; Gelhorn et al., 2008; Grant et al., 2007; Kaczynski Pollock \& Martin, 1999; Schuckit et al., 2008) lead to questioning the boundary of DSM-IV alcohol abuse and the DO status. Overall, severe symptom characteristics of DOs and impairment to be expected have a lot to commend it, and drinking patterns and risks for progression provide additional support for incorporating DOs in AUD diagnosis. Hence, the DO status could serve as a meaningful contribution for the identification of early stages of AUD development (Harford, Yi et al., 2010; Hasin \& Paykin, 1999; Kaczynski Pollock \&Martin, 1999; Wells et al., 2006). The recent proposed revisions of DSM-V AUD category, which merges former DSMIV AD and AA, while incorporating former DOs experiencing two symptoms (APA, 2010), may be a first useful step. Incorporating DOs into the AUD classification system closes a gap, now comprising subjects that experience serious drinking problems. There has been concern about the problem of false positive diagnoses of alcohol use disorders in adolescents (Caetano \& Babor, 2006), however current investigations show that chances of diagnosing subjects wrongly positive are rather small (Gelhorn et al., 2008; Harford et al., 2010; Kessler et al., 2003), which reassures our findings.

Also, differences between $\mathrm{DO}$ and $\mathrm{AA}$ on the one hand and $\mathrm{AD}$ on the other hand, which clearly differ from each other in drinking patterns and impairment, should not be overlooked. Other studies support this conclusion. From a clinical perspective, Ray et al. (2008) compared patient groups of DOs, subjects with AUDs and patients with no-AUD-symptoms. They found DOs to be younger, more dependent on Cannabis and more often offspring of a family with a history of alcoholism than those without symptoms; Still DOs were less likely to report poly drug use and were in clinical observations very different from patients with AUDs. In this study, the authors recommended to not combine DOs with AUDs.

A similar recommendation came from Hasin and Paykin (1999) investigating drinking levels, drug use, treatment and family history of alcoholism in an epidemiological setting. They found subjects with AUDs to be different in these variables. When comparing heavier drinkers among the subjects without symptoms against DOs they found no significant differences between these groups. Finally, McBride and Adamson (2010) suggested in their 
recent, national study on AUDs a further, clinical investigation of possible diagnosis categories to be able to allocate timely and cost-effective interventions.

That is why a gradational categorization and intervention strategy might be of more efficacious help than fitting the same diagnoses and following treatment towards DOs in adolescence and young adulthood with two symptoms as to subjects with AD fully experiencing the highest risk for further problems, extraordinarily high drinking patterns and impairment. We also strongly recommend a deeper exploration of the specifics, i.e. temporal course and predictors, of a DO status in adolescence and young adulthood. A longitudinal comparison of adolescent and adult DOs would be of most interest.

\subsection{Future investigations}

Future research should further investigate DO status in adolescence and young adulthood and its specific characteristics. Possibly specific symptoms (Harford et al., 2005), risk factors, and correlates would be of interest. The temporal course of the DO status and predictors of its stability and progression should be investigated (Bühringer et al., 2008). DO status in relation with other substances as cannabis or nicotine would be of interest. Alcohol related impairment should be addressed in greater detail and with a broader focus on possibly typical types of impairment for adolescents and young adults, i.e. in school.

\subsection{Limitations}

Impairment was assessed only regarding the last four weeks. Since we investigated lifetime and follow-up AUD status, impairment reports may not have been related to the time period with the greatest burden of symptoms. Also there is no guarantee for the impairment reports being connected to alcohol use. In general, self-report measures may be influenced by subjective biases like social desirability, memory biases or misunderstandings, especially for the age of adolescence (Caetano \& Babor, 2006; Chung \& Martin, 2005). To minimize such influences we used the response lists, visual aids, such as time lines for dating, and cognitive probe techniques (commitment probes) embedded in the CIDI (Lachner et al., 1998; Wittchen, Lachner et al., 1998). Greater Munich is a relatively wealthy region in Germany with relatively permissive policies and attitudes towards alcohol use which makes generalization to regions with different alcohol-related policies and attitudes difficult. We did not address comorbid disorders, which should be considered in future investigations.

\section{Role of funding sources}

Funding and support: this paper was prepared in the context of the project 'Community-based need evaluation II and allocation and transfer' (primary investigator: H.-U. Wittchen) of the German Addiction Research Network ASAT (Allocating Substance Abuse Treatments to Patient Heterogeneity). Contact information: Email: asatkoordination@mpipsykl.mpg.de (http://www.asat-verbund.de). This work is a further part of the Early Developmental Stages of Psychopathology (EDSP) Study and is funded by the German Federal Ministry of Education and Research (BMBF) project nos. 01EB9405/6, 01EB 9901/6, EB01016200, $01 E B 0140$ and 01EB0440. Parts of the fieldwork and analyses were supported additionally by grants from the Deutsche Forschungsgemeinschaft (DFG) LA1148/1-1, WI2246/1-1, WI 709/7-1 and WI 709/8-1. 


\section{Contributors}

Author Maike Grabitz analyzed the data and wrote the first draft of the manuscript. Authors Silke Behrendt and Gerhard Buehringer supervised the first author in any regard. Author Jens Klotsche gave statistical support. Authors Roselind Lieb and Hans-Ullrich Wittchen are the principal investigators of the study. All authors contributed to and have approved the final manuscript.

\section{Conflict of interest}

The authors do neither have a conflict of interest related to this paper, nor in general.

\section{Acknowledgments}

Funding and support: this paper was prepared in the context of the project 'Community-based need evaluation II and allocation and transfer' (primary investigator: H.-U. Wittchen) of the German Addiction Research Network ASAT (Allocating Substance Abuse Treatments to Patient Heterogeneity). Contact information: E-mail: asatkoordination@mpipsykl.mpg.de (http://www.asat-verbund.de). This work is a further part of the Early Developmental Stages of Psychopathology (EDSP) Study and is funded by the German Federal Ministry of Education and Research (BMBF) project nos 01EB9405/6, 01EB 9901/6, EB01016200, 01EB0140 and 01EB0440. Parts of the fieldwork and analyses were supported additionally by grants from the Deutsche Forschungsgemeinschaft (DFG) LA1148/1-1, WI2246/1-1, WI709/7-1 and WI 709/8-1.

The principal investigators are Dr Hans-Ulrich Wittchen and Dr Roselind Lieb. Core staff members of the EDSP group are: Dr Kirsten von Sydow, Dr Gabriele Lachner, Dr Axel Perkonigg, Dr Peter Schuster, Dr Michael Höfler, Dipl.-Psych. Holger Sonntag, Dr Tanja Brückl, Dipl.-Psych. Elzbieta Garczynski, Dr Barbara Isensee, Dr Agnes Nocon, Dr Chris Nelson, Dipl.-Inf. Hildegard Pfister, Dr Victoria Reed, Dipl.-Soz. Barbara Spiegel, Dr Andrea Schreier, Dr Ursula Wunderlich, Dr Petra Zimmermann, Dr Katja Beesdo, Dr Antje Bittner, Dr Silke Behrendt and Dr Susanne Knappe. Scientific advisers are Dr Jules Angst (Zurich), Dr Jürgen Margraf (Basel), Dr Günther Esser (Potsdam), Dr Kathleen Merikangas (NIMH, Bethesda), Dr Ron Kessler (Harvard, Boston) and Dr Jim van Os (Maastricht).

This work is based on the diploma thesis of Dipl.-Psych. Maike Grabitz. The diploma thesis has been supervised by Dr Silke Behrendt. 


\section{Appendix A}

Table 1

Baseline lifetime and follow-up prevalence rates of diagnostic status ( $\mathrm{N}=2039$ ).

\begin{tabular}{|c|c|c|c|c|c|c|c|c|c|}
\hline & & \multicolumn{2}{|l|}{$\mathrm{NS}^{b}$} & \multicolumn{2}{|l|}{$\mathrm{DO}^{6}$} & \multicolumn{2}{|l|}{$A A^{d}$} & \multicolumn{2}{|l|}{$A D^{e}$} \\
\hline & & $\overline{N^{f}}$ & $x w^{k}$ & $\overline{N^{i}}$ & tawe & $N^{f}$ & tawe & $\overline{N^{f}}$ & $x w^{t}$ \\
\hline \multirow[t]{3}{*}{$\mathrm{T}_{0}{ }^{4}$} & $\begin{array}{l}\text { Total } \\
\text { Age }\end{array}$ & 1581 & 72.55 & 198 & 11.93 & 171 & 9.89 & 89 & 5.63 \\
\hline & 14-17 & 846 & 88.11 & 39 & 5.69 & 30 & 4.39 & 13 & 1.80 \\
\hline & $18-24$ & 735 & 6592 & 159 & 1459 & 141 & 12.24 & 76 & 7.26 \\
\hline \multirow[t]{3}{*}{$\mathrm{T}_{2}{ }^{\mathrm{A}}$} & $\begin{array}{l}\text { Total } \\
\text { Age }\end{array}$ & 1346 & 68.31 & 256 & 11.39 & 303 & 13.28 & 134 & 7.02 \\
\hline & $14-17$ at $\mathrm{T}_{0}$ & 555 & 6004 & 135 & 1447 & 174 & 18.35 & 64 & 7.14 \\
\hline & $18-24$ at $\mathrm{T}_{0}$ & 791 & 7183 & 121 & 1008 & 129 & 11.12 & 70 & 6.97 \\
\hline \multirow[t]{3}{*}{$\mathrm{T}_{3}{ }^{*}$} & $\begin{array}{l}\text { Total } \\
\text { Age }\end{array}$ & 1589 & 8033 & 252 & 1083 & 24 & 0.85 & 174 & 8.00 \\
\hline & 14-17 at $\mathrm{T}_{0}$ & 676 & 74.14 & 144 & 1442 & 17 & 1.69 & 91 & 9.75 \\
\hline & $18-24$ at $\mathrm{T}_{0}$ & 913 & 82.97 & 108 & 929 & 7 & 0.49 & 63 & 7.25 \\
\hline
\end{tabular}

${ }^{a} T_{0} / T_{2} / T_{3}$ measurement waves ( $T_{0} ;$ lifetime prevalence rates; $T_{2}$ and $T_{3}$; follow-up prevalence rates).

NS, subjects without symptoms.

c DO, diagnostic orphans (subjects with one or two alcohol dependence symptoms, but no alcohol abuse or dependence diagnosis).

AA, subjects with DSM-N a lcohol abuse

AD, subjects with DSM-N alcohol dependence.

$N$, number of cases

$z w$, weighted percentages.

Table 2

Diagnostic status at 4- and 10-year follow-up by base line diagnostic status and diagnostic status at 10-year follow-up by 4-year follow-up diagnostic status ( $\mathrm{N}=2,039$ ).

\begin{tabular}{|c|c|c|c|c|c|c|c|c|c|c|c|c|c|}
\hline \multirow[t]{2}{*}{$\begin{array}{l}\text { Status } \\
\text { at } T_{0}{ }^{*}\end{array}$} & \multicolumn{4}{|c|}{$\begin{array}{l}\text { Diagnostic status at } T_{2} \text { by baseline diagnostic } \\
\text { status" }\end{array}$} & \multicolumn{4}{|c|}{$\begin{array}{l}\text { Diagnostic status at } \mathrm{T}_{3} \text { by baseline diagnostic } \\
\text { status }^{*}\end{array}$} & \multirow[t]{2}{*}{$\begin{array}{l}\text { Status } \\
\text { at } \mathrm{T}_{2}{ }^{*}\end{array}$} & \multicolumn{4}{|c|}{$\begin{array}{l}\text { Diagnostic status at Tsby four-year diagnostic } \\
\text { status * }\end{array}$} \\
\hline & $\overline{\mathrm{NS}^{\mathrm{b}}}$ & $\mathrm{DO}^{\mathrm{e}}$ & $\mathrm{AA}^{\mathrm{d}}$ & $\mathrm{AD}^{e}$ & $\mathrm{NS}^{b}$ & $\mathrm{DO}^{\mathrm{f}}$ & $\mathrm{AA}^{\mathrm{d}}$ & $\mathrm{AD}^{e}$ & & $\mathrm{NS}^{b}$ & $\mathrm{DO}^{6}$ & $\mathrm{AM}^{\mathrm{d}}$ & $\mathrm{AD}^{e}$ \\
\hline $\mathrm{NS}^{4} \cdot \mathrm{i}$ & & & & & & & & & $\mathrm{NS}^{4 \cdot \mathrm{i}}$ & & & & \\
\hline$N^{f}$ & 1,133 & 186 & 215 & 47 & 1,296 & 187 & 20 & 77 & $N^{f}$ & 1,192 & 114 & 9 & 31 \\
\hline$x w^{x}$ & 7599 & 10.15 & 1158 & 2.28 & 86.15 & 961 & 0.90 & 3.35 & $x w^{x}$ & 89.96 & 7.32 & 0.54 & 2.18 \\
\hline DOF & & & & & & & & & $\mathrm{DO}^{\mathrm{F}}$ & & & & \\
\hline$N^{4}$ & 93 & 43 & 44 & 18 & 138 & 36 & 1 & 23 & $N^{f}$ & 168 & 67 & 2 & 19 \\
\hline$x w^{x}$ & 49.57 & 21.83 & 2047 & 8.13 & 71.22 & 1837 & 0.23 & 10.17 & $x w^{x}$ & 69.09 & 25.23 & 0.62 & 5.06 \\
\hline$m r^{h}$ & $*$ & 404 & 3.00 & 6.40 & -5 & 2.35 & 0.46 & 4.69 & $m r^{n}$ & $\approx$ & 365 & 1.03 & 2.36 \\
\hline $\begin{array}{l}(C, 1)^{i} \\
A^{d}\end{array}$ & & $(2,6-6,4)$ & $(19-48)$ & $(3.2-12.9)$ & & $(1.5-3.8)$ & $(0.1-3.7)$ & $(2,6-8.4)$ & $\left(C, I^{i}\right.$ & & $(2,4-5.5)$ & $(02-50)$ & $(1.2-4.5)$ \\
\hline$N^{t}$ & 87 & 27 & 44 & 13 & 117 & 29 & 3 & 22 & $N^{4}$ & 190 & $\pi$ & 13 & 29 \\
\hline$x w a$ & 5402 & 14.37 & 2464 & 6.98 & 70.42 & 1682 & 1.68 & 11.08 & $x w^{a}$ & 65.99 & 22.22 & 3.07 & 8.72 \\
\hline $\begin{array}{l}m r^{h} \\
(C, I)^{i}\end{array}$ & $\therefore$ & $\begin{array}{l}23 \\
(1.4-3.9)\end{array}$ & $\begin{array}{l}3.04 \\
(19-48)\end{array}$ & $\begin{array}{l}4.5 \\
(2.1-9.7)\end{array}$ & $\therefore$ & $\begin{array}{l}202 \\
(1.3-3.3)\end{array}$ & $\begin{array}{l}3.06 \\
(0.9-104)\end{array}$ & $\begin{array}{l}4.74 \\
(2.6-8.7)\end{array}$ & $\begin{array}{l}m r^{k} \\
(C, I)^{i}\end{array}$ & $\therefore$ & $\begin{array}{l}294 \\
(2.0-4.4)\end{array}$ & $\begin{array}{l}4.61 \\
(19-11.1)\end{array}$ & $\begin{array}{l}3.68 \\
(2.0-6.9)\end{array}$ \\
\hline $\mathrm{AD}^{e}$ & & & & & & & & & $\mathrm{AD}^{e}$ & & & & \\
\hline $\begin{array}{l}N^{t} \\
x^{2} w^{z}\end{array}$ & 33 & $0^{* 2}$ & $0^{*}$ & 56 & 37 & $0^{*}$ & $0^{* z}$ & 52 & $N^{4}$ & 39 & $0^{* 2}$ & $0^{*}$ & $\begin{array}{l}35 \\
6801\end{array}$ \\
\hline $\begin{array}{l}x w^{2} \\
m r^{b}\end{array}$ & $\begin{array}{ll}34.13 \\
-* 1\end{array}$ & $-{ }^{*}$ & $-*$ & $\begin{array}{l}65.87 \\
75.37\end{array}$ & 42.04 & $000^{*}$ & $0.00^{2 / 2}$ & $\begin{array}{l}57.96 \\
54.51\end{array}$ & $\begin{array}{l}x w^{z} \\
m r^{b}\end{array}$ & 31.99 & -7 & $=*$ & $\begin{array}{l}68.01 \\
65.54\end{array}$ \\
\hline$(C, 1)^{i}$ & & $--^{*}$ & $\mathrm{Ak}^{\mathrm{k}}$ & $(35.3-170.0)$ & -7 & $=2$ & $=*$ & $(27.5-108.0)$ & $(C, I)^{i}$ & $\therefore$ & $-{ }^{*}$ & $z^{* k}$ & $(349-123,1)$ \\
\hline
\end{tabular}

${ }^{A}, T_{0} / T_{2} / T_{3}$, measurement waves ( $T_{0}$ : lifetime prevalence rates; $T_{2}$ and $T_{3}$ : follow-up prevalence rates).

NS, subjects without symptoms

- DQ diagnostic orphans.

¿AA, subjects with DSM-IV alcohol abuse.

AD, subjects with DSM-IV alcohol dependence.

${ }^{4} \mathrm{~N}$, number of cases.

Z $x w$, weighted percentages

" $\mathrm{rm}$, relative risk ratios.

- C.I, 95\% confidence interva L

$\mathrm{j*}$ Relative risk ratios and respective confidence intervals are not reproduced for subjects without symptoms (NS) for being reference category.

$k$ * In agreement with current DSM-N, subjects with fomer a kohol dependence could not receive a diagnosis of abuse at a subsequent wave. Subjects with a history of al $\infty$ hol dependence who reparted 1-2 alcohol dependence symptoms at a subsequent wave, were classified as alcohol dependent at the subsequent wave. 
Table 3

Drinking frequency and drinking quantity by diagnostic status at each assessment wave.

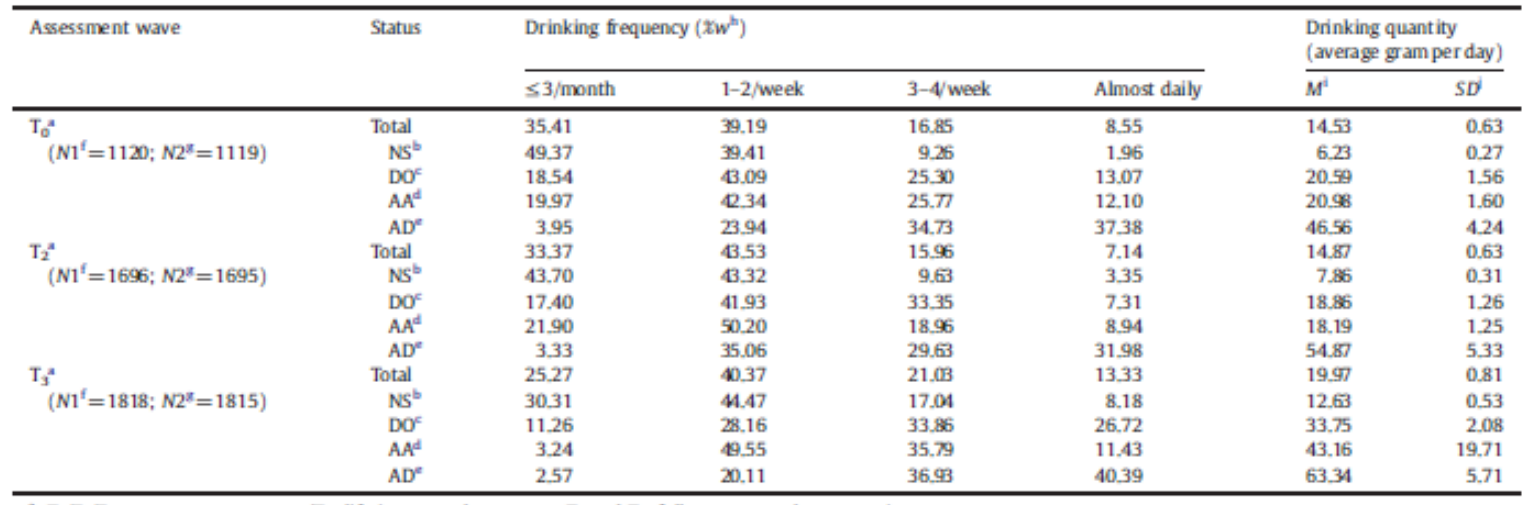

$\mathrm{T}_{0} / \mathrm{T}_{2} / \mathrm{T}_{3}$, measurement waves ( $\mathrm{T}_{0}$ : lifetime prevalence rates; $\mathrm{T}_{2}$ and $\mathrm{T}_{3}$; follow-up prevalence rates).

NS, subjects without symptoms

EQ diagnostic orphans.

¿AA, subjects with DSM-IV alcohol abuse.

- AD, subjects with DSM-IV alcohol dependence.

if $\mathrm{N}$, number of cases with drin king frequency information.

${ }^{*} N$, number of cases with drinking quan tity information.

in $x$, weighted row? percentages

i $M$, mean

isD, standard deviation.

Table 4

Results of regressions analyses on drinking frequencies by diagnostic status.

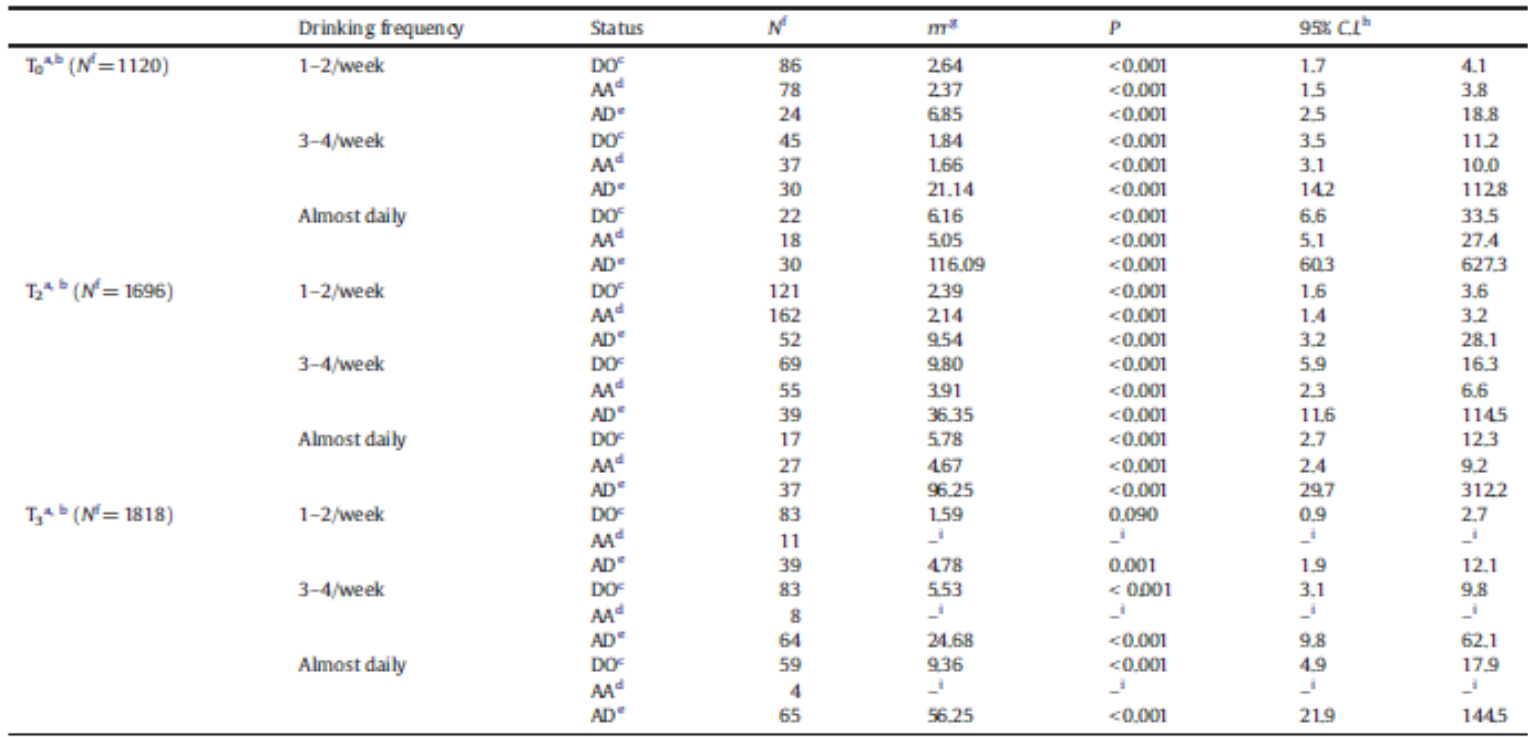

${ }^{*} T_{0} / T_{2} / T_{3}$, measurement waves ( $T_{0}$ lifetime prevalence rates; $T_{2}$ and $T_{3}$ : follow-up prevalence rates).

bubjects without symptoms (NS) and drinking frequency "less than four times a month" are not reproduced for being reference categories.

¿ DO, diagnostic orphans.

AA, subjects with DSM-IV alcohol abuse.

- AD, subjects with DSM-IV alcohol dependence.

${ }^{4} \mathrm{~N}$, number of cases

$m$, relative risk ratics.

h $C, I$, confidence interval

insufficient power. 
Results of regressions on drinking quantities (average gram ethanol per day) by diagnostic status.

\begin{tabular}{|c|c|c|c|c|c|c|}
\hline & Status & Coefficient ${ }^{z}$ & $P$ & $958 \mathrm{C.} \mathrm{I}^{\mathrm{b}}$ & & Betr-coefficient \\
\hline$T_{0}{ }^{a b}$ & $\mathrm{DO}^{\mathrm{F}}$ & 12.36 & $<0.001$ & 85 & 162 & 0.21 \\
\hline \multirow[t]{2}{*}{$\left(N^{f}=1119\right)$} & $\mathrm{AA}^{\mathrm{d}}$ & 12.39 & $<0.001$ & 88 & 161 & 0.19 \\
\hline & $\mathrm{AD}^{e}$ & 37.20 & $<0.001$ & 27.7 & 467 & 045 \\
\hline \multirow{2}{*}{$\left(N^{f}=1695\right)$} & $\mathrm{AA}^{\mathrm{d}}$ & 8.64 & $<0.001$ & 60 & 113 & 0.12 \\
\hline & $\mathrm{AD}^{e}$ & 44.39 & $<0.001$ & 31.7 & 57.1 & 047 \\
\hline $\mathrm{T}_{3}{ }^{\mathrm{ab}}$ & $\mathrm{DO}^{\mathrm{F}}$ & 18.56 & $<0.001$ & 142 & 229 & 0.18 \\
\hline$\left(N^{f}=1.815\right)$ & $\mathrm{AA}^{\mathrm{d}}$ & 27.72 & 0.058 & -10 & 564 & 0.08 \\
\hline
\end{tabular}

" $\mathrm{T}_{0} / \mathrm{T}_{2} / \mathrm{T}_{3}$ measurement waves ( $\mathrm{T}_{0}$ l lifetime prevalence rates: $\mathrm{T}_{2}$ and $\mathrm{T}_{3}$ : follow-up prevalence rates)

Subjects without symptoms (NS) and drinking frequency "less than four times a month" are not reproduced for being reference categories.

DO, diagnostic orphans.

AM, subjects with DSM-IV alcohol abuse

AD, subjects with DSM-IV alcohol dependence

$N$, number of cases

Linear regression coefficients of drinking quantity, mean difference in average consumed gram of pure alcohol per day.

C.L, confidence interval

\section{References}

- Alcohol and Public Policy Group (2003). Alcohol: No ordinary commodity. A summary of the book. Addiction, 98, 1343-1350.

- APA - American Psychiatric Association (2000). Diagnostic and Statistical Manual of Mental Disorders - DSM-IV-TR (4th edition, Text Revision). Washington, DC: American Psychiatric Association.

- APA - American Psychiatric Association (2010). DSM-V Development: Proposed Revisions on Alcohol-Use Disorders. Retrieved February 18, 2010, from http://www.dsm5.org/ProposedRevisions/Pages/proposedrevision.. aspx?rid=452\#

- Bailey, S. L., Martin, C. S., Lynch, K. G., \& Pollock, N. K. (2000). Reliability and concurrent validity of DSM-VI subclinical symptom ratings for alcohol use disorders among adolescents. Alcoholism, Clinical and Experimental Research, 24(12), 1795-1802.

- Behrendt, S., Wittchen, H.-U., Höfler, M., Lieb, R., Ping Low, N. C., Rehm, J., et al. (2008). Risk and speed of transitions to first alcohol dependence symptoms in adolescents: A 10-year longitudinal community study in Germany. Addiction, 103, 1638-1647.

- Bonomo, Y. A., Bowes, G., Coffey, C., Carlin, J. B., \& Patton, G. C. (2004). Teenage drinking and the onset of alcohol dependence: A cohort study over seven years. Addiction, 99, $1520-1528$.

- Bühringer, G., Wittchen, H. -U., Gottlebe, K., Kufeld, C., \& Goschke, T. (2008). Why people change? The role of cognitive control processes in the onset and cessation of substance abuse disorders. International Journal of Methods in Psychiatric Research, 17(S1), S4-S15.

- Caetano, R., \& Babor, T. F. (2006). Diagnosis of alcohol dependence in epidemiological surveys: An epidemic of youthful alcohol dependence or a case of measurement error? Addiction, 101(1), 111-114.

- Chung, T., \& Martin, C. S. (2001). Classification and course of alcohol problems among adolescents in addictions treatment programs. Alcoholism, Clinical and Experimental Research, 25, 1734-1742.

- Chung, T., \& Martin, C. S. (2005). What were they thinking? Adolescents interpretations of DSM-IV alcohol dependence symptom queries and implications for diagnostic validity. Drug and Alcohol Dependence, 80, 191-200.

- Crews, F., He, J., \& Hodge, C. (2007). Adolescent cortical development: A critical period of vulnerability for addiction. Pharmacology, Biochemistry, and Behavior, 86, 189-199.

- Dawson, D. A., Grant, B. F., \& Harford, T. C. (1995). Variation in the association of alcohol consumption with five DSM-IV alcohol problem domains. Alcoholism, Clinical and Experimental Research, 19, 66-74.

- Gelhorn, H., Hartman, C., Sakai, J., Stallings, M., Young, S., Rhee, S. H., et al. (2008). Toward DSM-V: An item response theory analysis of the diagnostic process for DSM-IV alcohol abuse and dependence in adolescents. American Academy of Child and Adolescent Psychiatry, 47(11), 1329-1339. 
- Grant, B. F., et al. (2007). DSM-IV alcohol dependence and abuse: Further evidence of validity in the general population. Drug and Alcohol Dependence, 86, 154-166.

- Harford, T. C., Grant, B. F., Yi, H. -Y., \& Chen, C. M. (2005). Patterns of DSM-IV alcohol abuse and dependence criteria among adolescents and adults: Results from the 2001 National Household Survey on Drug Abuse. Alcoholism, Clinical and Experimental Research, 29(5), $810-828$.

- Harford, T. C., Yi, H. -Y., \& Grant, B. F. (2010). The five-year diagnostic utility of "diagnostic orphans" for alcohol use disorders in a national sample of young adults. Journal of Studies on Alcohol and Drugs, 71(3), 410-417.

- Hasin, D. S., \& Grant, B. F. (2004). The co-occurrence of DSM-IV alcohol abuse in DSM-IV alcohol dependence: Results of the National Epidemiologic Survey on Alcohol and Related Conditions on heterogeneity that differ by population subgroup. Archives of General Psychiatry, 61, 891-896.

- Hasin, D. S., \& Paykin, A. (1999). Dependence symptoms but no diagnosis: Diagnostic 'orphans' in a 1992 national sample. Drug and Alcohol Dependence, 53, 215-222.

- Höfler, M. (2004). Statistik in der Epidemiologie psychischer Störungen. Berlin: Springer.

- Holly, A., Türk, D., Nelson, C. B., Pfister, H., \& Wittchen, H.-U. (1997). Prävalenz von Alkoholkonsum, Alkoholmissbrauch und -abhängigkeit bei Jugendlichen und jungen Erwachsenen. Zeitschrift für Klinische Psychologie, 26, 171-178.

- Holly, A., \& Wittchen, H. -U. (1998). Patterns of use and their relationship to DSM-IV abuse and dependence of alcohol among adolescents and young adults. European Addiction Research, 4, 50-57.

- Kaczynski Pollock, N., \& Martin, C. S. (1999). Diagnostic Orphans: Adolescents with alcohol symptoms who do not qualify for DSM-VI abuse or dependence diagnosis. The American Journal of Psychiatry, 156(6), 897-901.

- Kessler, R. C., Merikangas, K. R., Berglund, P., Eaton, W. W., Koretz, D. S., \& Walters, E. E. (2003). Mild disorders should not be eliminated from the DSM-V. Archives of General Psychiatry, 60, 1117-1122.

- Lachner, G., Wittchen, H. -U., Perkonnigg, A., Holly, A., Schuster, P., Wunderlich, U., et al. (1998). Structure, content and reliability of the Munich-Composite International Diagnostic Interview (M-CIDI). European Addiction Research, 4, 28-41.

- Lewinsohn, P. M., Rohde, P., \& Seeley, J. R. (1996). Alcohol consumption in high school adolescents: Frequency of use and dimensional structure of associated problems. Addiction, 91(3), 375-390.

- Li, T. -K., Hewitt, B. G., \& Grant, B. F. (2007). Is there a future for quantifying drinking in the diagnosis, treatment and prevention of alcohol use disorders? Alcohol and Alcoholism, 41(4), 57-63.

- Lieb, R., Isensee, B., von Sydow, K., \& Wittchen, H. -U. (2000). The early developmental stages of psychopathology study (EDSP): A methodological update. European Addiction Research, 6, 170-182.

- Maser, J. D., Norman, S. B., Zisook, S., Everall, I. P., Stein, M. B., Schettler, P. J., et al. (2009). Psychiatric nosology is ready for a paradigm shift in DSM-V. Clinical Psychology: Science and Practice, 16, 24-40.

- Mathurin, P., \& Deltenre, P. (2009). Effect of binge drinking on the liver: An alarming public health issue? Gut, 58, 613-617.

- McBride, O., \& Adamson, G. (2010). Are subthreshold alcohol dependence symptoms a risk factor for developing DSM-IV alcohol use disorders? A three-year prospective study of 'diagnostic orphans' in a national sample. Addictive Behaviors, 35(6), 586-592.

- McBride, O., Adamson, G., Bunting, B. P., \& McCann, S. (2009a). Characteristics of DSMVI alcohol diagnostic orphans: Drinking patterns, physical illness, and negative life events. Drug and Alcohol Dependence, 99, 272-279.

- McBride, O., Adamson, G., Bunting, B. P., \& McCann, S. (2009b). Diagnostic orphans: Comparing self-report lifetime course to groups with DSM-IV alcohol use and dependence. Addictive Behaviors, 34, 86-91. 
- Moss, H. B. (2008). Special section: Alcohol and brain development. Clinical and Experimental Research, 32(3), 427-429.

- Nelson, C. B., \& Wittchen, H. -U. (1998). DSM-IV alcohol disorders in a general population sample of adolescents and young adults. Addiction, 97(3), 1065-1077.

- Okoro, C. A., Brewer, R. D., Naimi, T. S., Moriarty, T. G., Giles, W. H., \& Mokdad, A. H (2004). Binge drinking and health-related quality of life: Do popular perceptions match reality? American Journal of Preventive Medicine, 26, 230-233.

- Pregibon, D. (1980). Goodness of link tests for generalized linear models. Applied Statistics, 29, 15-24.

- $\quad$ Ray, L. A., Miranda, R., Jr., Chelminski, I., Young, D., \& Zimmerman, M. (2008). Diagnostic orphans for alcohol use disorders in a treatment-seeking psychiatric sample. Drug and Alcohol Dependence, 96, 187-191.

- Rehm, J., Taylor, B., \& Patra, J. (2006). Volume of alcohol consumption, patterns of drinking and burden of disease in the European region 2002. Addiction, 101, 1086-1095.

- Rehm, J., Room, R., Graham, K., Monteiro, M., Gmel, G., \& Sempos, C. T. (2003). The relationship of average volume of alcohol consumption and patterns of drinking to burden of disease: An overview. Addiction, 98, 1209-1228.

- Royall, R. (1986). Model robust inference using maximum likelihood estimators. International Statistical Review, 54, 221-226.

- Saha, T. D., Stinson, F. S., \& Grant, B. F. (2007). The role of alcohol consumption in future classifications of alcohol use disorders. Drug and Alcohol Dependence, 89, 82-92.

- Saunders, J. B. (2006). Substance dependence and non-dependence in the Diagnostic and Statistic Manual of Mental Disorders (DSM) and the International Classification of Diseases (ICD): Can an identical conceptualization be achieved? Addiction, 101(1), 48-58.

- Schuckit, M. A., Danko, G. P., Smith, T. L., Bierut, L. J., Bucholz, K. K., Edenberg, H. J., et al. (2008). The prognostic implications of DSM-IV abuse criteria in drinking adolescents. Drug and Alcohol Dependence, 97, 94-104.

- StataCorp (2007). Stata Statistical Software: Release 10.0. College Station, TX: StataCorp LP.

- Wells, J. E., Horwood, L. J., \& Fergusson, D. M. (2006). Stability and instability in alcohol diagnosis from ages 18 to 21 and ages 21 to 25 years. Drug and Alcohol Dependence, 81, $157-165$.

- Wittchen, H.-U., Lachner, G., Wunderlich, U., \& Pfister, H. (1998). Structure, content and reliability of the Munich-Composite International Diagnostic Interview (M-CIDI). European Addiction Research, 4, 28-41.

- Wittchen, H.-U., Perkonigg, A., Lachner, G., \& Nelson, C. B. (1998). Early developmental stages of psychopathology study (EDSP): Objectives and design. European Addiction Research, 4, 18-27.

- Wittchen, H.-U., \& Pfister, H. (Eds.). (1997). DIA-X-Interviews: Manual für ScreeningVerfahren und Interview; Interviewheft Längsschnittuntersuchung (DIA-X-Lifetime); Ergänzungsheft (DIA-X-Lifetime); Interviewheft Querschnittuntersuchung (DIA-X-Monate); Ergänzungsheft (DIA-X-Monate); PC-Programm zur Durchführung des Interviews (Längsund Querschnittuntersuchung); Auswertungsprogramm. Frankfurt: Swets and Zeitlinger.

- World Health Organization (2008). The global burden of disease: 2004 update. Geneva: WHO Press.

- Young, S. E., Corley, R. P., Stallings, M. C., Rhee, S. H., Crowley, T. J., \& Hewitt, J. K. (2002). Substance use, abuse and dependence in adolescence: Prevalence, symptom profiles and correlates. Drug and Alcohol Dependence, 68, 309-322. 